\title{
The contrasting genetic architecture of wing size and shape in Drosophila melanogaster
}

\author{
A. S. GILCHRIST \& L. PARTRIDGE \\ Department of Biology, Galton Laboratory, University College London, London NW1 2HE, U.K.
}

\begin{abstract}
Surprisingly little is known about the genetic architecture of body size in natural populations of Drosophila melanogaster. Using both generation means and triple-test-cross analyses, we investigated the genetic architecture of wing size (an indicator of body size) and wing shape in a naturally occurring body size cline. For wing size, we found significant epistatic genetic variance and evidence of past directional selection for increased body size. While wing shape also exhibits significant epistatic genetic variance, there was no indication of directional selection, suggesting instead a history of optimizing selection. Our results support the idea that epistatic variance may be more common in natural populations than was once suspected. Also, our results suggest substantial directional selection on wing size but not shape.
\end{abstract}

Keywords: directional selection, Drosophila melanogaster, epistasis, genetic architecture, wing shape, wing size.

\section{Introduction}

Body size is of central importance in evolution and ecology, and it has been study extensively in both artificial and natural environments. Numerous allometric relationships between life history, physiological and behavioural traits and body size have been reported across species (e.g. Schmidt-Nielsen, 1984). Various trade-offs affecting body size have been identified (Stearns, 1992). Although artificial selection experiments provide numerous insights into aspects of the evolution of body size, the generality of the findings is necessarily limited. Attempts to understand the how and why of evolution must eventually involve studies of natural populations.

In Drosophila, in particular, surprisingly little is known about the quantitative genetics of body size of natural populations, apart from its high heritability (Coyne \& Beecham, 1987; Prout \& Barker, 1989; Ruiz et al., 1991; Thomas \& Barker, 1993). Our intention in this study was to answer some additional and important questions regarding the evolution of body size in Drosophila melanogaster in a natural body-size cline. First, using wing area as a measure of body size, we questioned the importance of epistasis in population

*Correspondence and present address: Fruit Fly Research Centre, School of Biological Sciences A12, University of Sydney, NSW 2006, Australia. E-mail: stuartg@bio.usyd.edu.au divergence. The answer is relevant not only to the shifting balance theory of evolution, but also to questions regarding the evolution of mating systems and conservation genetics (see Whitlock et al., 1995; Fenster et al., 1997). Secondly, what sort of selection (either directional or optimizing) is likely to be the predominant form of natural selection acting on the trait? Body size in D. melanogaster has an intermediate optimum value, largely determined by correlations with fecundity, development time and larval survival (Roff, 1981). Thus, although appearing to be under optimizing selection, the optimizing selection on body size is only apparent (Falconer, 1989): it is not clear what type of selection acts directly on genes determining body size within the constraints imposed by correlated characters.

In addition to wing area, we also analysed wing shape. Although a number of investigators have documented natural variation in wing shape, little is known about the evolutionary genetics of wing shape within species. Weber (1990) found evidence consistent with optimizing selection on wing shape in natural populations, while Bitner-Mathé \& Klaczko (1999) found high heritability for shape in D. mediopunctata. Despite recent advances in the understanding of the aerodynamics of the wings of smaller insects (Lehmann \& Dickinson, 1998), virtually nothing is known about the functional implications of variation of wing morphology (Grodnitsky, 1999). This makes any inferences about the action of natural selection on shape difficult. Further investigation into 
the genetics and selective forces affecting shape would help to determinine whether or not natural variation is adaptive.

In a previous study, we investigated clinal variation in wing area using a generation means analysis (Gilchrist \& Partridge, 1999). In the present work, we have extended our earlier study, using both a tripletest-cross analysis and a generation means analysis to investigate clinal variation in wing shape as well as wing size. Together, these designs allow the additive, dominance and epistatic components affecting the traits to be estimated. Using this information, we can characterize the genetic architecture of the traits and draw inferences about the type of natural selection that has acted on the traits.

\section{Methods}

\section{Flies}

Parental lines were derived from populations sampled from extreme ends of the eastern Australian body-size cline (James et al., 1995). The smaller body-size, northern population came from Innisfail, Queensland (Inn, $17.30^{\circ} \mathrm{S}$ ), while the larger body size, southern populations came from Cygnet, Tasmania (Cyg, $\left.43.08^{\circ} \mathrm{S}\right)$. Both populations were sampled in January 1997 and maintained as outbred bottle populations. All flies used for measurement were picked as first instar larvae and raised in vials of unyeasted standard medium, at a constant density (30 larvae per vial), conditions under which competition is minimal and body size maximized. All flies emerging from each vial were frozen for later measurement.

A number of isogenic lines, derived from the Cyg and Inn populations, were constructed in late 1997 in a twostage process to avoid problems associated with lowlevel recombination when the three major chromosomes are balanced simultaneously. First, individual X-chromosomes were homogenized using an FM7 balancer stock. Secondly, pairs of second and third chromosomes were homogenized using a SM5/b $w^{\mathrm{V} 1}$; TM3/TM6B stock. Separate X-isogenic lines and II-and III-isogenic lines were subsequently combined to produce lines that were isogenic for all three major chromosomes. Both isogenic lines used in the present experiments were smaller (although not significantly so) than the outbred stock from which they were derived. This is consistent with low values of inbreeding depression for body size within populations of D. melanogaster (Tantaway, 1957; Fowler \& Whitlock, 1999). The smaller isogenic line was approximately $82 \%$ the size of the larger line, the same relative difference that exists in the outbred stocks (approximately $84 \%$ ).

\section{Measurements}

We used wing area as an estimate of body size, because the two characters are highly correlated (Reeve \& Robertson, 1952). Wing measurements were performed as detailed in Gilchrist \& Partridge (1999). Briefly, wing images (one per fly) were captured using a compound microscope-mounted video camera. Using the OBJECTIMAGE program (Vischer, 1998), coordinates of 10 wing landmarks were recorded and the wing area calculated based on the polygon shown in Fig. 1. From the same landmark data we also extracted the principle components (PCs) of shape variation for use as shape variables. PCs were computed using covariance matrices after the landmark data had undergone a Procrustes superimposition, a process of reflection, scaling (using centroid size) and rotation that produced a superimposition minimizing deviations from the overall mean shape. The process is described in detail in Dryden \& Mardia (1998).

\section{Experimental designs}

We measured the genetic components of both wing size and shape using two complementary biometrical designs. The first, a generation means analysis, was performed on the cross between two extreme populations from a natural body-size cline. This analysis estimated net genetic effects on the mean phenotypic values of the hybrid generations (as detailed in Kearsey \& Pooni, 1996). The second experimental design, the triple-test-cross (TTC) design, analysed genetic variance components, rather than means, in the cross between isogenic lines from the cline ends (Kearsey \& Jinks, 1968; Kearsey, 1980). These two approaches (i.e. a means analysis and a variance analysis) are complementary

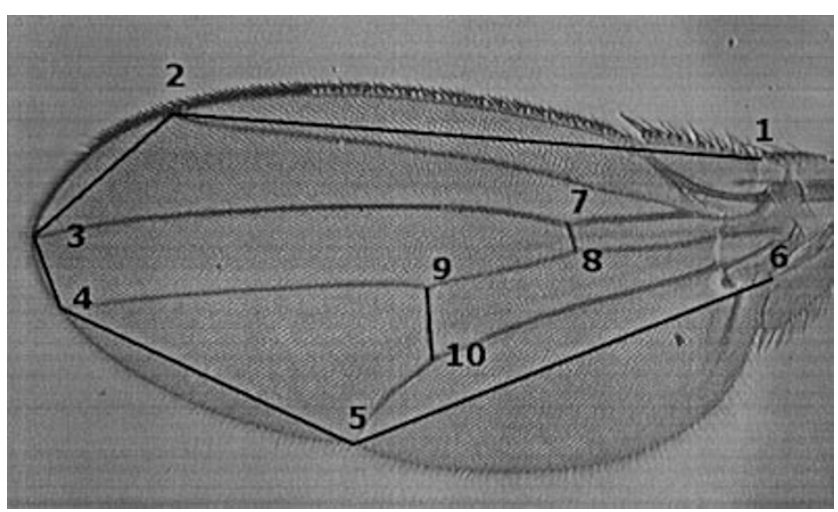

Fig. 1 The landmarks used as the basis of both wing size and shape measurements. Wing size was calculated using the landmarks 1-6, while shape calculations also included the four crossvein landmarks. 
because they measure different aspects of underlying gene action and interaction (Jinks, 1979; Fenster et al., 1997). As the means analysis measures net genetic effects on means while the TTC measures variance components, their parameters are not correlated. Thus, for example, when the effects of increasing and decreasing dominant alleles are spread evenly between the two populations, the means analysis will show a zero net dominance (i.e. ambidirectional dominance), whereas a TTC analysis may detect significant dominance variance (because the variance is unaffected by the net direction of dominance). Alternatively, when dominance is directional rather than ambidirectional, the means analysis has the advantage of showing the direction of the dominance, something that cannot be inferred easily from the variance analysis. Similarly, the means analysis may detect epistatic interactions near fixation, while the variance resulting from the same alleles may be very small. Either analysis taken alone may produce an ambiguous indication of the genetic architecture, but together provide a clearer picture on the genetic architecture of the trait.

\section{Generation means analysis}

This analysis was performed on data from Gilchrist \& Partridge (1999), where models describing wing size, but not wing shape, were presented. The generation means analysed were the two parental populations and their $F_{1}, F_{2}$ and back-cross generations. Keeping reciprocals separate, 14 generations were raised and wing traits measured. Using a weighted least-squares analysis (Kearsey \& Pooni, 1996; Lynch \& Walsh, 1998), composite additive ([a]), dominance ([d]), digenic epistatic ([aa], [ad] and [dd]) and maternal effects were calculated. Goodness-of-fit tests (using $\chi^{2}$-values) were then used to determine the model (incorporating some or all of these composite effects) that best described the observed generation means. Changes made to the method used in Gilchrist \& Partridge (1999) involved a new parameter accounting for the additive effect of the $\mathrm{X}$ chromosome, $\left[\mathrm{a}_{\mathrm{X}}\right]$, that differs between male and females. In addition, the sampling variance was calculated separately for each generation, accounting for possible effects of variation in within-generation variance for different genotypes (Robertson \& Reeve, 1953).

For the shape analysis, PC1 and PC2 were extracted from the two outbred parental populations. These provided our basic shape variables, capturing over $40 \%$ of the shape variation between the cline end populations (Table 1). Figure 2 shows the shape change associated with $\mathrm{PC} 1$ and $\mathrm{PC} 2$. PC1 describes a relative enlargement of the posterior region of the wing coupled with displacement of the posterior crossvein. PC2
Table 1 The percentage variance accounted for by shape principal components $1-5$

\begin{tabular}{lcc}
\hline PC & Females & Males \\
\hline 1 & 23.9 & 23.4 \\
2 & 18.7 & 18.7 \\
3 & 15.3 & 14.4 \\
4 & 10.8 & 10.8 \\
5 & 9.3 & 8.4 \\
\hline
\end{tabular}
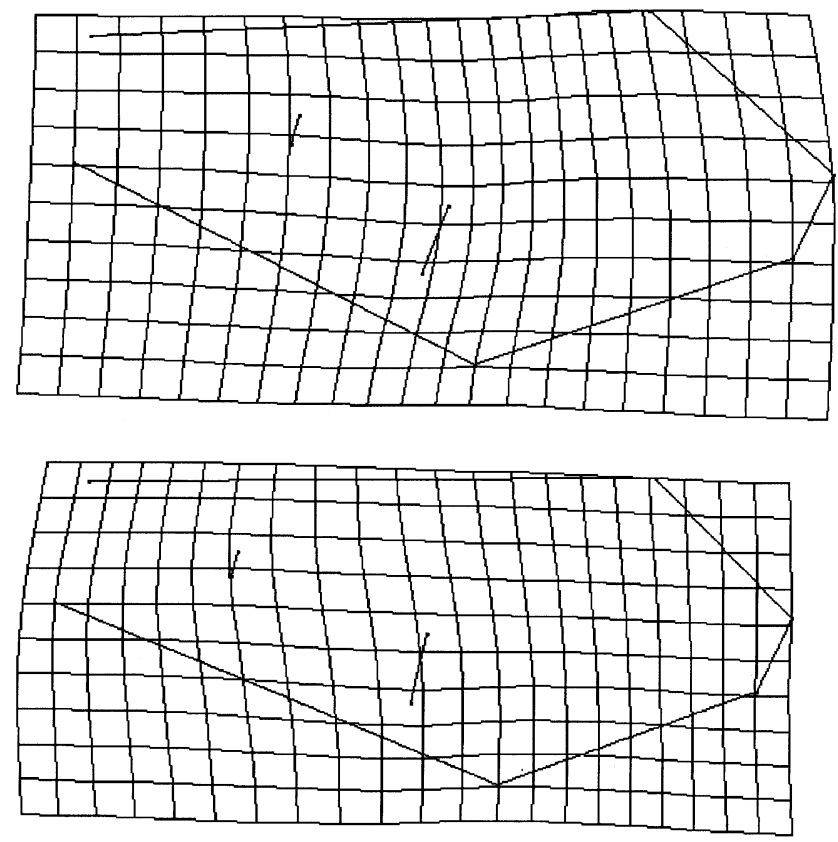

Fig. 2 The transformation grids describing the shape variation measured for female wings. The shape variation shown represents the distortions necessary to move from the larger parental wing shape to the smaller parental wing shape for PC1 (upper) and PC2 (lower). The reference points are the same as those indicated in Fig. 1.

describes an arching of the wing along the longitudinal axis (D. melanogaster wings appear to have very little affine shape variation). For both the means analysis and the TTC, shape measurements were collected by projecting the Procrustes co-ordinates of the hybrid generations onto the parental PC axes. Strictly speaking, PCs are valid only for the populations from which they were derived and are not expected to be orthogonal in other groups. However, we were not interested in distinguishing between $\mathrm{PC} 1$ and $\mathrm{PC} 2$; instead we regarded $\mathrm{PC} 1$ and PC2 as different aspects of a single character (i.e. shape). Therefore, their independence was not crucial to our analysis. Nevertheless, when the Procrustes co-ordinates of the hybrid generations are projected onto the parental PC axes, PC1 and PC2 remain uncorrelated $(r=-0.040$, 
$P=0.07)$. Also, the variance of the landmarks did not significantly differ between the parental and hybrid populations. Therefore, PC1 and PC2 were adopted as two distinct, but not necessarily independent shape measures.

\section{TTC analysis (variance analysis)}

Individual $\mathrm{F}_{2}$ males were crossed sequentially to groups of six $\mathrm{P} 1, \mathrm{P} 2$ or $\mathrm{F}_{1}$ females (the three test crosses). All test crosses to the same tester $\left(\mathrm{P} 1, \mathrm{P} 2\right.$ or $\left.\mathrm{F}_{1}\right)$ were performed on the same day and all larvae reared on the same batch of food medium. In practice, the progeny production of these crosses was very poor. As a result, many crosses failed to produce sufficient progeny for measurement, while the low numbers of progeny generally precluded replication of vials. Only data from $F_{2}$ males that produced at least eight measured individuals of either sex in all three test crosses were used. This allowed the data to be analysed as a completely balanced two-way ANOVA, simplifying the partitioning of mean squares. The TTC analysis provides a test for epistatic variance which was partitioned into a $V_{\text {aa }}$ component and a combined $V_{\text {ad }} / V_{\text {dd }}$ component (using the method set out in Kearsey $\&$ Pooni, 1996). Parameters of the variance analysis are indicated as $V_{\mathrm{a}}, V_{\mathrm{d}}, V_{\text {aa }}$, etc.

The outbred parental PC axes were also used for the TTC analysis. The Procrustes transformed TTC landmarks were rotated so that the mean co-ordinates were the same as those of the Procrustes transformed outbred parental landmarks. The Procrustes transformed TTC landmarks were then projected onto the parental PC axes. The result of this procedure is that the TTC tested for the same pattern of shape variation that was measured in the outbred populations. The raw shape variation between the parental isogenic lines represents a biased sample of the shape variation between the outbred populations. Therefore, if we had used PCs extracted directly from those data, in effect, we would have been analysing a different shape character. Because we were interested only in the outbred shape variation and not a biased sample, we again considered that projection onto the outbred parental PC axes was justified. Although PC1 and PC2 were significantly correlated in the TTC (females, $r=0.16$; males, $r=-0.12$ ), their independence was not crucial to our analysis.

\section{Software}

Full Procrustes superimpositions were performed using the programs MORPHOMETRIKA 007 (Walker, 1998) and MORPHOLOGIKA 1.1 (O'Higgins \& Jones, 1999). Statistical analyses were performed using JMP 3.2.2 for the Macintosh (SAS Institute, 1994). In order to visualize the shape changes attributable to each source of variation, we used MORPHOLOGIKA 1.1 (O'Higgins \& Jones, 1999), which allowed the effects of continuous variation in a single PC to be visualized using wireframe models while other PCs were be held at zero.

\section{Results}

\section{Wing size}

Area data were transformed by taking natural logs. This transformation produced a slightly lower epistatic variance and eliminated a small increase of variance with size (in the males only). The results of the generation means analysis are shown in Table 2. As expected, the significant parameters are the same as those presented in Gilchrist \& Partridge (1999), despite the data being transformed and the use of additional parameters. For the females, the additive effects were both autosomal and $\mathrm{X}$-linked. There was net dominance for increasing alleles. The [ad] component was also reflected in the TTC analysis (Table 3), where the combined $V_{\mathrm{ad}} / V_{\mathrm{dd}}$ component was highly significant. The model describing male wing area was similar, with directional dominance for larger wings and significant [ad] interaction. Analysing the data as a North Carolina III design (in which $\mathrm{F}_{2}$ individuals are backcrossed to both parents, but not to the $F_{1}$ tester; Kearsey \& Pooni, 1996), estimates of $V_{\mathrm{a}}$ and $V_{\mathrm{d}}$ were obtained (Tables 4 and 5). Although these estimates were biased by the presence of epistatic variance, they indicate significant $V_{\mathrm{d}}$ for wing area in both sexes, as expected on the basis of the significant [d] in the means analysis. The significant directional dominance for larger wings and large amounts of interaction in both sexes are indicative of past directional selection on wing area.

\section{Wing shape}

Our basic shape variables were PC1 and PC2, calculated separately for each sex. The only significant correlation with wing area occurred in females for PC2 $\left(r=0.35_{\text {[281] }}\right.$, $P<0.001)$. This allometric variation could be the result of two possible underlying causes: (i) an underlying developmental constraint, i.e. the genetic mechanism controlling shape imposing particular shape variation as wing size increases; or (ii) parallel selection with wing area. If PC2 represents a developmental constraint, we have no expectation for its genetic architecture. If it is selected with size, then PC2 may have a similar genetic architecture resembling that of wing area. PC1, however, was not consistently correlated with size. Accordingly, it is unlikely to be subject either to developmental 
Table 2 The estimates of composite genetic effects affecting mean wing area (ln transformed) and wing shape (PC1 and PC2). Subscript X denotes the $\mathrm{X}$ chromosome and subscript $\mathrm{M}$ denotes a maternal effect. Note the absence of dominance effects from the PC models

\begin{tabular}{|c|c|c|c|c|c|c|}
\hline & \multicolumn{3}{|c|}{ Females $\left(\times 10^{4}\right)$} & \multicolumn{3}{|c|}{ Males $\left(\times 10^{4}\right)$} \\
\hline & $\ln (\mathrm{WA})$ & $\mathrm{PC} 1$ & PC2 & $\ln (\mathrm{WA})$ & PC1 & $\mathrm{PC} 2$ \\
\hline $\mathrm{m}$ & 2443.6 & -5.6 & 21.8 & -205.3 & -22.6 & 5.0 \\
\hline [a] & $728.1 * * *$ & $11.6^{* *}$ & & $803.9 * * *$ & & $20.5^{* * *}$ \\
\hline$\left[a_{x}\right]$ & & & $43.7 * * *$ & & $-18.1 * * *$ & \\
\hline [d] & $219.3 * * *$ & & & $127.3^{*}$ & & \\
\hline [a.a] & & & $-36.5 * * *$ & & $19.6 * *$ & \\
\hline$\left[a_{x} \cdot a_{x}\right]$ & & $-15.7 * * *$ & $17.3 * * *$ & & & \\
\hline [a.d] & $-329.7 * * *$ & & & $-460.9^{* * *}$ & & \\
\hline$\left[\mathrm{a}_{\mathrm{m}}\right]$ & & & & & $-36.5^{* * *}$ & \\
\hline$\left[\mathrm{d}_{\mathrm{m}}\right]$ & $-189.7 * * *$ & $9.3^{*}$ & & $-208.7^{* * * *}$ & & $14.1 * * *$ \\
\hline [c] & & & $-12.5^{* * * *}$ & -86.8 & & \\
\hline $\mathrm{Y}$ & & & & & $11.3 * * *$ & $-6.2^{* *}$ \\
\hline$\chi^{2}$ & $18.73^{*}$ & $29.23 * *$ & $41.52 * * *$ & $25.31 * *$ & $40.95^{* * *}$ & $41.87 * * *$ \\
\hline
\end{tabular}

$* P<0.05 ; * * P<0.01 ; * * * P<0.001$.

Table 3 Triple test cross analysis of variance for wing area (ln transformed) and wing shape (PC1 and PC2), showing total epistasis partitioned between $\mathrm{V}_{\mathrm{aa}}$ and $\mathrm{V}_{\mathrm{ad}} / \mathrm{V}_{\mathrm{dd}}$

\begin{tabular}{|c|c|c|c|c|c|c|c|}
\hline & \multirow[b]{2}{*}{ d.f. } & \multicolumn{2}{|c|}{$\ln (\mathrm{WA})$} & \multicolumn{2}{|c|}{$\mathrm{PC} 1$} & \multicolumn{2}{|c|}{$\mathrm{PC} 2$} \\
\hline & & MS & $F$ & $\operatorname{MS}\left(\times 10^{4}\right)$ & $F$ & $\operatorname{MS}\left(\times 10^{4}\right)$ & $F$ \\
\hline \multicolumn{8}{|l|}{ Females } \\
\hline$V_{\text {а }}$ & 1 & 0.0151 & $2.78 \mathrm{NS}$ & 3.009 & $2.84 \mathrm{NS}$ & 0.592 & $<1 \mathrm{~ns}$ \\
\hline$V_{\mathrm{ad}}, V_{\mathrm{dd}}$ & 32 & 0.0051 & $2.42 * * *$ & 0.998 & $1.45 \mathrm{NS}$ & 1.949 & $2.31 * * *$ \\
\hline All epistasis & 33 & 0.0054 & $2.57 * * *$ & 1.059 & $1.53 *$ & 1.908 & $2.26 * * *$ \\
\hline within FS families & 759 & 0.0021 & & 0.690 & & 0.844 & \\
\hline \multicolumn{8}{|l|}{ Males } \\
\hline$V_{\text {aa }}$ & 1 & 0.0719 & $9.91 * * *$ & 0.410 & $<1 \mathrm{NS}$ & 1.212 & $<1 \mathrm{~ns}$ \\
\hline$V_{\mathrm{ad}}, V_{\mathrm{dd}}$ & 36 & 0.0055 & $2.57 * * *$ & 0.851 & $1.40 \mathrm{NS}$ & 2.050 & $2.86^{* * *}$ \\
\hline All epistasis & 37 & 0.0073 & $3.42 * * *$ & 0.839 & $1.38 \mathrm{NS}$ & 2.027 & $2.83 * * *$ \\
\hline within FS families & 851 & 0.0021 & & 0.609 & & 0.717 & \\
\hline
\end{tabular}

NS, not significant $(P>0.05) ;{ }^{*} P<0.05 ; * * * P<0.001$.

\begin{tabular}{lrccrrrrr}
\hline & \multicolumn{3}{c}{ Females } & & \multicolumn{3}{c}{ Males } \\
\cline { 2 - 4 } \cline { 6 - 8 } & d.f. & MS $\left(\times 10^{4}\right)$ & F & & d.f. & MS $\left(\times 10^{4}\right)$ & $F$ \\
\hline Testers & 1 & 34.8 & $30.85^{* * *}$ & & 1 & 217.3 & $350.9^{* * * *}$ \\
F2s (additive) & 32 & 3.99 & $7.45^{* * *}$ & & 36 & 2.56 & $5.62^{* * *}$ \\
TxF2s (dominance) & 32 & 1.13 & $2.11^{* * *}$ & & 36 & 0.619 & $1.36 \mathrm{NS}$ \\
within FS families & 528 & 0.535 & & & 592 & & 0.456 & \\
\hline
\end{tabular}

Table 4 Analysis of variance for PC1 data when treated as a North Carolina III design

NS, not significant $(P>0.05) ; * * * P<0.001$.

constraint or size-related selection. PC1 may represent a shape component free to respond to natural selection.

For both PC1 and PC2, the means analysis provided no sufficient model for either sex (Table 2), indicating the presence of higher order interactions and/or linkage. In both sexes there were significant [a], [a $\mathrm{a}_{\mathrm{x}}$, [aa] and $\left[a_{x} a_{x}\right]$ components and maternal effects. In contrast to wing area, X-linked alleles appear to have a much larger 
Table 5 Estimates of additive and dominance variance for the three traits indicated. Significance was calculated following (Kearsey, 1980)

\begin{tabular}{|c|c|c|c|c|c|c|}
\hline & \multicolumn{2}{|c|}{ Wing area } & \multicolumn{2}{|c|}{$\mathrm{PC} 1$} & \multicolumn{2}{|c|}{$\mathrm{PC} 2$} \\
\hline & Females & Males & Females & Males & Females & Males \\
\hline$V_{\mathrm{a}}^{*}\left(\times 10^{4}\right)$ & $33.4 * * *$ & $31.1 * * *$ & $0.86^{* * *}$ & $0.53 * * *$ & $0.73 * *$ & $1.03 * *$ \\
\hline$V_{\mathrm{d}} *\left(\times 10^{4}\right)$ & $4.1 * *$ & $5.2 * *$ & $0.07 *$ & $0.02 \mathrm{NS}$ & $0.09 *$ & $0.02 \mathrm{NS}$ \\
\hline$h^{2}$ & 0.81 & 0.75 & 0.71 & 0.61 & 0.61 & 0.80 \\
\hline
\end{tabular}

NS, not significant $(P>0.05) ;{ }^{*} P<0.05 ;{ }^{* *} P<0.01 ; * * * P<0.001$ effect on shape. Notably, there were no significant [d] or [dd] effects apparent for either PC in either sex. In the variance analysis (Table 3), PC1 showed significant epistatic variance only in females. The partitioning did not detect the predominant form of epistatic variance, and therefore the significant [aa] effects detected in the means analysis were not reflected in the variances. A possible explanation for this discrepancy is that the additive-by-additive component is the consequence of a large number of individually small interactions between many genes, a situation that can result in significant [aa] but nonsignificant $V_{\text {aa }}$ (Kearsey \& Pooni, 1996). Using a North Carolina Design III (shown for PC1 in Table 4), estimates of $V_{\mathrm{a}}$ and $V_{\mathrm{d}}$ were obtained as for wing area (Table 5). In the case of the males, these estimates were unbiased because there was no significant epistasis, while the female estimates were biased to some degree by the small amount of epistatic variance. $V_{\mathrm{d}}$ for PC1 was not significant in males and $V_{\mathrm{d}}$ was small and only marginally significant in females. Given that dominance for $\mathrm{PC} 1$ is either small or absent, the genetic architecture of $\mathrm{PC} 1$ is predominantly additive, suggesting a history of optimizing rather than directional selection. In both sexes, the heritability of $\mathrm{PC} 1$ was high (Table 5).

Estimates of $V_{\mathrm{a}}$ and $V_{\mathrm{d}}$ were also obtained for $\mathrm{PC} 2$, although these estimates are necessarily biased because of the highly significant epistatic effects on the variances (Tables 3 and 5). For PC2, male $V_{\mathrm{d}}$ was again not significantly different from zero, while for females $V_{\mathrm{d}}$ was again small but significant $(P=0.04)$. This suggests that, for males at least, the absence of dominance effects on the means was in fact because of the absence of dominance variance, not ambidirectional dominance. Again, the low levels of dominance variance are suggestive of optimizing rather than directional selection on wing shape.

\section{Discussion}

Using a biometrical analysis of both generation means and variances of wing size and shape we have shown, first, that the wing size divergence of $D$. melanogaster populations in the eastern Australia cline involves significant epistatic variance. Secondly, in comparing the genetic architectures of wing area and wing shape we have shown that, while size is likely to have been subject to directional selection, shape is likely to have been subject to optimizing selection.

Interest in epistasis is founded squarely on its role in Wright's shifting balance theory (Wright, 1977). Epistasis is proposed to have a vital role in shaping multiple fitness peaks for interbreeding populations. Ideally, the existence of multiple peaks could be established simply by measuring epistasis for fitness. However, such direct measurement is extremely difficult, if not impossible (Whitlock et al., 1995). Instead, measurement of the role of epistasis in characters that are both more amenable to measurement and closely related to fitness produces circumstantial evidence for the importance of epistasis in shaping fitness profiles. In D. melanogaster, similar natural clines in wing area exist on most continents, suggesting that wing area must be highly correlated with fitness. Our results demonstrate that genes determining wing area show significant amounts of epistatic interaction and that there is also significant epistatic genetic variance. Previous results have shown that the epistatic parameters (determined only from a means analysis) vary considerably between continents (Gilchrist \& Partridge, 1999). This variety implies that different genetic combinations can generate similar size divergence, involving either different alleles or the same alleles at different frequencies. The presence of significant amounts of epistatic genetic variance suggests that the evolutionary response to size selection may involve selection of alternate combinations of interacting alleles. The genetic landscape for wing area may have many alternate peaks. The relevance of this result lies in the degree to which epistasis for size corresponds to epistasis for fitness. There is evidence of correlations between additive chromosomal effects on size and fertility, but correlations between interaction terms for size and fitness are much harder to demonstrate (e.g. Cavicchi et al., 1989).

The second point to emerge from our results concerns the evolutionary history of different aspects of wing morphology. The predominant form of selection affecting the traits was inferred from the genetic architecture of both wing size and shape. Different forms of selection, either directional or optimizing, operating over sufficiently long periods are expected to produce 
recognizable patterns in underlying genetic parameters. A view formulated by Mather, and originally based on Fisher's ideas of the evolution of dominance, is that directional selection should result in relatively larger dominance components for fitness traits than for morphological traits (e.g. Mather, 1966; Mather, 1983). Although the evolution of dominance as originally envisaged is open to serious question (Orr, 1991), a number of studies have shown patterns of genetic architecture consistent with the original expectation, i.e. higher dominance variance for directionally selected traits (e.g. Breese \& Mather, 1960; Kearsey \& Kojima, 1967; Kearsey \& Barnes, 1970). A likely cause of increased dominance in fitness traits is that alleles with positive effects on fitness will be selected, regardless of their degree of dominance. The erosion of additive genetic variance under directional selection is also expected to increase the relative amount of dominance variance (Crnokrak \& Roff, 1995), while selection on dominance at other alleles may occur in some circumstances (Mayo \& Burger, 1997). An additional expectation is that duplicate epistasis should also arise in directionally selected traits, again to moderate the effects of new unfavourable alleles. By contrast, traits under optimizing selection are expected to have a predominantly additive architecture, with less pronounced dominance components. Because these traits have an intermediate optimum, alleles with dominance that move the trait mean in either direction away from the optimum will have equivalent, detrimental effects on fitness. Therefore, dominance will not be favoured and will be either reduced, absent or ambidirectional.

For body size, previous results have shown that D. melanogaster has a predominantly additive architecture, indicating optimizing selection (Kearsey \& Kojima, 1967). However, these results were observed in crosses between laboratory strains, chosen without regard for size. Because we deliberately selected populations showing extreme body size divergence, these results are not strictly comparable. Our results suggest that the divergence of the Cyg and Inn populations has involved selection for dominant increasing alleles. At a given point along the cline, optimal body size would be determined by the balance of correlated characters, but the presence of directional dominance for body size would ensure a higher proportion of individuals were at the maximum possible body size permitted by the pattern of correlated characters. This may be particularly advantageous at lower temperatures, as indicated by the finding that genetically larger flies may have increased survival and lifetime fecundity at cooler temperatures (McCabe \& Partridge, 1997).

Shape, however, is more complex. Although many studies have documented shape change in a variety of
Drosophila species (Alonso \& Munoz, 1984; Cavicchi et al., 1991; Bitner-Mathé et al., 1995; Imasheva et al., 1995; Bublii et al., 1996; Pezzoli et al., 1997; Baylac \& Penin, 1998; Haas \& Tolley, 1998; Huey et al. 2000), there is little evidence indicating that natural shape change is adaptive. Because the general wing structure of five longitudinal veins and three cross-veins is common to the entire family Drosophilidae (Wheeler, 1981), shape might be thought to be highly canalized. Also, allometric shape variation is a common feature of most morphological structures. Therefore, shape variation may be limited by phylogenetic constraints and (assuming that the allometric shape variation is not selected) a significant portion of the observed phenotypic variation may be a consequence of developmental constraints (in the form of allometry). Any adaptive shape change would then involve only the remaining nonallometric shape component. While there are significant shape differences between populations of D. melanogaster at this level (Gilchrist et al. 2000), we lack even hypothetical functional explanations for such shape variation (Grodnitsky, 1999). For the present, there appears little chance of explaining observed shape variation in functional terms.

Instead of attempting a functional explanation, we have examined this variation from a biometrical viewpoint. On the basis of earlier results showing that the variation in shape, although significant, is small (Gilchrist et al. 2000), it was hypothesized that shape variation may simply represent drift around an optimum. Our results support this hypothesis. The genetic architecture of both PC1 and PC2 suggests an evolutionary history of optimizing rather than directional selection, implying an intermediate optimal phenotype. If small-scale shape variation is not adaptive, this optimal phenotype may instead be a product of developmental constraints or 'intrinsic' canalization (Gibson \& Wagner, 2000). Canalization of the phenotype (i.e. reduced variation around the mean) may explain why the range of drift was so narrow, yet detectable. Our view of shape variation as a simple additive character, with little dominance or interaction, is consistent with other investigations of wing shape. Bitner-Mathé \& Klaczko (1999) found that nonallometric PCs in D. mediopunctata have high heritability. A recent QTL analysis of artificially selected shape change found shape to be influenced by genes dispersed along the third chromosome, with nearly additive effects in heterozygotes (Weber et al., 1999). Two models were proposed to explain their results, both involving many genes (11 at least) with largely additive effects and either no or cancelling interactions. In a cross between two laboratory strains, Zimmerman et al. (2000) also found 34 possible shape QTLs with largely additive affects. If 
shape is a simple additive character, then it may prove useful for the study of morphological variation. For example, once QTL intervals have been identified, candidate loci could be screened using complementation tests. However, in traits showing significant amounts of interaction and/or dominance, results can be ambiguous despite attempts to control for different genetic backgrounds by prior backcrossing (Gurganus et al., 1999). Where the effects of natural variation are entirely additive, complementation testing may be considerably easier.

\section{Acknowledgements}

We thank Giselle Geddes for invaluable technical assistance. This work was supported the Natural Environment Research Council (UK).

\section{References}

ALONSO, A. AND MUNOZ, A. 1984. Biometric characterization of some wing measurement in Drosophila melanogaster. Drosoph. Inf. Serv., 60, 47-48.

BAYLAC, M. AND PENIN, X. 1998. Wing static allometry in Drosophila simulans males (Diptera, Drosophilidae) and its relationships with developmental compartments. Acta zool. Hung., 44, 97-112.

BITNER-MATHÉ, B. C. AND KLACZKo, L. B. 1999. Size and shape heritability in natural populations of Drosophila mediopunctata: temporal and microgeographical variation. Genetica, 105, 35-42.

BITNER-MAthé, B. C., Peixoto, A. A. AND KlACZKo, L. B. 1995. Morphological variation in a natural population of Drosophila mediopunctata: altitudinal cline, temporal changes and influence of chromosome inversions. Heredity, 75, 54-61.

BREESE, E. L. AND MATHER, K. 1960. The organization of polygenic activity within a chromosome in Drosophila. Heredity, 14, 375-399.

BUBLII, O. A., IMASHEVA, A. G. AND LAZEBNY, O. E. 1996. Variation of a set of wing characters in natural populations of Drosophila melanogaster. Genetika, 32, 1513-1520.

CAVICCHI, S., GIORGI, G., NATALI, V. AND GUERRA, D. 1991. Temperature-related divergence in experimental populations of Drosophila melanogaster III. Fourier and centroid analysis of wing shape and relationship between shape variation and fitness. J. Evol. Biol., 4, 141-159.

CAVICCHI, S., GUERRA, D., NATALI, V., PEZZOLI, C. AND GIORGI, G. 1989. Temperature-related divergence in experimental populations of Drosophila melanogaster. II. Correlation between fitness and body dimensions. J. evol. Biol., 2, 235-251.

COYNE, J. A. AND BEECHAM, E. 1987. Heritability of two morphological characters within and among natural- populations of Drosophila melanogaster. Genetics, 117, 727-737.

CRNOKRAK, P. AND ROFF, D. A. 1995. Dominance variance: associations with selection and fitness. Heredity, 75, $530-540$.
DRYDEN, I. L. AND MARDIA, K. V. 1998. Statistical Shape Analysis. Wiley, Chichester.

FALCONER, D. S. 1989. Introduction to Quantitative Genetics. Longman, London.

FENSTER, C. B., GALlOWAY, L. F. AND CHAO, L. 1997. Epistasis and its consequences for the evolution of natural populations. Trends Ecol. Evol., 12, 282-286.

FOWLER, K. AND WHITLOCK, M. C. 1999. The distribution of phenotypic variance with inbreeding. Evolution, 53, 1143-1156.

GIBSON, G. AND WAGNER, G. 2000. Canalization in evolutionary genetics: a stabilizing theory. Bioessays, 22, 372-380.

GILCHrist, A. S., AZEVEDO, R. B. R., PARTRIDGE, L. AND O'HIGGINS, P. 2000. Adaptation and constraint in the evolution of Drosophila melanogaster wing shape. Evol. Dev., 2, 114-124.

GILCHRIST, A. S. AND PARTRIDGE, L. 1999. A comparison of the genetic basis of wing size divergence in three parallel body size clines of Drosophila melanogaster. Genetics, 153, 1775-1787.

GRODNITSKy, D. L. 1999. Form and Function of Insect Wings. The Johns Hopkins University Press, Baltimore.

GURGANUS, M. C., NUZHDIN, S. V., LEIPS, J. W. AND MACKAY, T. F. C. 1999. High-resolution mapping of quantitative trait loci for sternopleural bristle number in Drosophila melanogaster. Genetics, 152, 1585-1604.

HAAS, H. L. AND TOLLEY, K. A. 1998. Geographic variation of wing morphology in three Eurasian populations of the fruit fly, Drosophila lummei. J. Zool., 245, 197-203.

HUEY, R. B., GILCHRIST, G. W., CARLSON, M. L., BERRIGAN, D. AND SERRA, L. 2000. Rapid evolution of a geographic cline in size in an introduced fly. Science 287, 308-309.

IMASHEVA, A. G., BUBLI, O. A., LAZEBNY, O. E. AND ZHIVOTOVSKY, L. A. 1995. Geographic differentiation in wing shape in Drosophila melanogaster. Genetica, 96, 303-306.

JAMES, A. C., AZEVEDO, R. B. R. AND PARTRIDGE, L. 1995. Cellular basis and developmental timing in a size cline of Drosophila melanogaster. Genetics, 140, 659-666.

JINKS, J. L. 1979. The biometrical approach to quantitative variation. In: Thompson, J. N. and Thoday, J. M. (eds) Quantitative Genetic Variation, Vol. 3c, pp. 81-109. Academic Press, New York.

KEARSEY, M. J. 1980. The efficiency of the North Carolina experiment III and selfing, backcrossing series for estimating additive and dominance variation. Heredity, 45, 73-82.

KEARSEY, M. J. AND BARNES, B. W. 1970. Variation for metrical characters in Drosophila populations. Heredity, 25, 11-21.

KEARSEY, M. J. AND JINKS, J. L. 1968. A general method of detecting additive, dominance and epistatic variation for metrical traits. I. Theory. Heredity, 23, 403-409.

KEARSEY, M. J. AND KOJIMA, K. 1967. The genetic architecture of body weight and egg hatchability in Drosophila melanogaster. Genetics, 56, 23-37.

KEARSEY, M. J. AND POONI, H. S. 1996. The Genetical Analysis of Quantitative Traits. Chapman \& Hall, London.

LEHMANN, F. O. AND DICKINSON, M. H. 1998. The control of wing kinematics and flight forces in fruit flies (Drosophila spp.). J. Exp. Biol., 201, 385-401. 
LYNCH, M. AND WALSh, B. 1998. Genetics and Analysis of Quantitative Traits. Sinauer Associates, Sunderland, MA.

MATHer, K. 1966. Variability and selection. Proc. R. Soc. B, 164, 328-340.

MATHER, K. 1983. Response to selection. In: Ashburner, M., Carson, H. L. and Thompson, J. N. (eds) Genetics and Biology of Drosophila, Vol. 3c, pp. 155-221. Academic Press, New York.

MAYO, O. AND BURGER, R. 1997. The evolution of dominance: a theory whose time has passed? Biol. Rev., 72, 97-110.

McCABE, J. AND PARTRIDGE, L. 1997. An interaction between environmental temperature and genetic variation for body size for the fitness of adult female Drosophila melanogaster. Evolution, 51, 1164-1174.

O'HIGGINS, P. AND JONES, N. 1999. Morphologika: tools for shape analysis. Release 1.1. University College London, London.

ORR, H. A. 1991. A test of Fisherís theory of dominance. Proc. Natl. Acad. Sci. U.S.A., 88, 11,413-11,415.

PEZZOLI, M. C., GUERRA, D., GIORGI, G., GAROIA, F. AND CAVICCHI, S. 1997. Developmental constraints and wing shape variation in natural populations of Drosophila melanogaster. Heredity, 79, 572-577.

PROUT, T. AND BARKER, J. S. F. 1989. Ecological aspects of the heritability of body size in Drosophila buzzatii. Genetics, 123, 803-813.

REEVE, E. C. R. AND Robertson, F. W. 1952. Studies in quantitative inheritance. II. Analysis of a strain of Drosophila melanogaster selected for long wings. J. Genet., 51, 276-316.

ROBERTSON, F. W. AND REEVE, E. C. R. 1953. Studies in quantitative inheritance. IV. The effects of substituting chromosomes from selected strains in different genetic backgrounds in Drosophila melanogaster. J. Genet., 51, 586-610.

ROFF, D. 1981. On being the right size. Am. Nat., 118, 405-422.

RUIZ, A., SANTOS, M., BARBADILlA, A., QUEZADA-DIAZ, J. E., HASSON, E. AND FONTDEVILA, A. 1991. Genetic variance for body size in a natural population of Drosophila buzzatii. Genetics, 128, 739-750.

SCHMIDT-NIElSEN, K. 1984. Scaling: Why Is Animal Size So Important? Cambridge University Press, Cambridge.

STEARnS, S. C. 1992. The Evolution of Life Histories. Oxford University Press, Oxford.

TANTAWY, A. O. 1957. Genetic variance of random-inbred lines of Drosophila melanogaster in relation to coefficients of inbreeding. Genetics, 42, 121-136.

THOMAS, R. H. AND BARKER, J. S. F. 1993. Quantitative genetic analysis of the body size and shape of Drosophila buzzatii. Theor. Appl. Genet., 85, 598-608.

VISCHER, N. O. E. 1998. Object-Image: An interactive image analysis program using structured point collection. Release 1.62n3. Universiteit van Amsterdam, Amsterdam.

WALKeR, J. A. 1998. Morphometrika: Macintosh software for geometric morphometric analysis of landmark data. Release 007. Field Museum, Chicago, IL.

WEBER, K., EISMAN, R., MOREY, L., PATTY, A., SPARKS, J., TAUSEK, M. AND ZENG, Z. B. 1999. An analysis of polygenes affecting wing shape on chromosome III in Drosophila melanogaster. Genetics, 153, 773-786.

WEBER, K. E. 1990. Selection on wing allometry in Drosophila melanogaster. Genetics, 126, 975-989.

WHEELER, M. R. 1981. The Drosophilidae: a taxonomic overview. In: Ashburner, M., Carson, H. L. and Thompson, J. N. (eds) Genetics and Biology of Drosophila, Vol. 3a, pp. 1-97. Academic Press, New York.

WHITLOCK, M. C., PHILLIPS, P. C., MOORE, F. B. G. AND TONSOR, S. J. 1995. Multiple fitness peaks and epistasis. Ann. Rev. Ecol. Syst., 26, 601-629.

Wright, s. 1977. Evolution and the Genetics of Populations, Vol. 3: Experimental Results and Evolutionary Deductions. University of Chicago Press, Chicago, IL.

ZIMMERMAN, E., PALSSON, A. AND GIBSON, G. 2000. Quantitative trait loci affecting components of wing shape in Drosophila melanogaster. Genetics, 155, 671-683. 